\title{
Durability and versatility of free lattismus dorsi muscle flap in leg defects
}

\section{Authors: Mohamed Abdel-Aal, Tarek El-Gammal, Samia M. A. Saied, Ahmed Elsherbiny and Ahmed Gaber.}

\begin{abstract}
Background: The objective of this study was to assess the outcome of free lattismus dorsi muscle flap used for soft tissue reconstruction of leg defects.

Methods: This prospective non-randomized study was conducted on 13 patients with leg defects of different causes attended emergency unit and outpatient clinic of plastic surgery department in Sohag University Hospital in the period between June 2013 and May 2014. Durability of coverage, flap success, infection, pain and overall satisfaction were studied.

Results: Complete flap survival was $92.3 \%$ with only one total flap loss.

Conclusion: The choice of the flap to cover leg defects should be tailored according to favorable criteria as regarding patient age, defect site, size and depth, presence or absence of infections.

The free lattismus dorsi muscle flap can cover huge sized defects, robust blood supply and less need for secondary thinning operations.
\end{abstract}

\section{Introduction}

Leg and foot reconstruction is challenging. Soft tissue management around the lower third of the leg poses a considerable challenge to the reconstructive surgeon because of the composite tissue defects, inadequate and tight local tissues and poor circulation [1]. Tendons, bone or hardware are frequently exposed because of the thinness of subcutaneous tissues, making skin grafting a poor option [2]. In the absence of specific knowledge of the pattern or reliability of the blood supply, the flaps were used initially as random pattern flaps constrained by length to width ratios to ensure viability [3]. The free flaps have been successfully used for lower extremity reconstruction for the past 40 years. Free Latissimus dorsi muscle flaps had been used in reconstruction of the complex lower extremity defects.

Patients and methods:
This is a prospective non-randomized study conducted on 13 patients with leg defects of different causes attended emergency unit and outpatient clinic of plastic surgery department in Sohag University Hospital in the period between June 2013 and May 2014.

Preoperatively, full history and examination was done. Initial debridement of the defect was done in cases with crushing injuries and also with delayed presentation.

Operative details as described elsewhere.

The minimum follow up period was 6 months, and patients were examined for durability of coverage, flap success, infection, pain and overall satisfaction.

Statistical analysis:

Data were analyzed using Statistical Package for Social Sciences (SPSS) software program .Qualitative variables were recorded as frequencies and percentages and were compared by chi-square test. Quantitative variables were presented as means \pm standard deviation (SD) and compared by student $\mathrm{t}$ - test. $\mathrm{P}$ value $<0.05$ will be significant. 
SOHAG MEDICAL JOURNAL

Vol. 21 No.3 october 2017

\section{Results}

The age incidence was ranged between 5 to 54 years with the mean age was 23.85 , the sex distribution was 9 males and 4 females. Defect size was ranged between 70 to 725 $\mathrm{cm}$ with the mean size was 184.15 and Table (1) show patients demographic data. Complete flap survival occurred in 12 cases which represent $92.3 \%$ success rate and 1 flap was completely lost and Table (2) show the success rate and the outcomes.

Table 1: Patients demographic data.

\begin{tabular}{|l|c|}
\hline Patient number & 13 \\
\hline Age (years) & $23.85+1-14.39$ \\
\hline Sex (percentage) & Male: $69.2 \%$ \\
& Female: $30.8 \%$ \\
\hline Defect size (cm.) & $184.15+1-70.56$ \\
\hline Defect site & $\begin{array}{c}\text { 4 middle } 113 \text { of the leg, } 4 \text { lower } 113 \text { of } \\
\text { the leg, } 3 \text { ankle, and } 2 \text { tendoachillis. }\end{array}$ \\
\hline Time before reconstruction & 6 months to 1.5 years \\
\hline Follow up time & $30.8 \%$ \\
\hline Smokers(percentage) & \\
\hline
\end{tabular}

Table 2: The success rate and outcomes.

\begin{tabular}{|c|c|}
\hline Ischemia time (minutes) $\mathrm{P}=0.02$ & $152.31+1-43.23$ \\
\hline Operation time (minutes) $\mathrm{P}=0.22$ & $348.46+1-55.51$ \\
\hline Hospital stay (days) $P=0.02$ & $16.08+\backslash-4.481$ \\
\hline Total flap loss (percentage) & $7.7 \%$ \\
\hline $\begin{array}{l}\text { Overall flap complications } \\
\text { (percentage) }\end{array}$ & $30.8 \%$ \\
\hline Donner site morbidity (percentage) & $30.8 \%$ \\
\hline Secondary procedures (percentage) & $15.4 \%$ \\
\hline
\end{tabular}




\section{Case Presentation}

\section{Case (1):}

Male patient, 28 years old, with roll over MCA and raw over the middle $1 \backslash 3$ of the Rt. leg. Defect size was $12 * 8 \mathrm{~cm}$. Soft tissue debridement and split-thickness skin graft was done immediately after trauma. The patient then develops chronic osteomylitis of the exposed tibia.

Free latisimus dorsi flap was done after bone and soft tissue debridement. Anastomosis was done end to end with post. tibial vessels. Ischemia time was 2 hours, total operation time was 5.5 hours, hospital stay was 15 days and the donor site was closed primary with no complications. Late post-operative results of the flap was satisfactory (Fig 1).

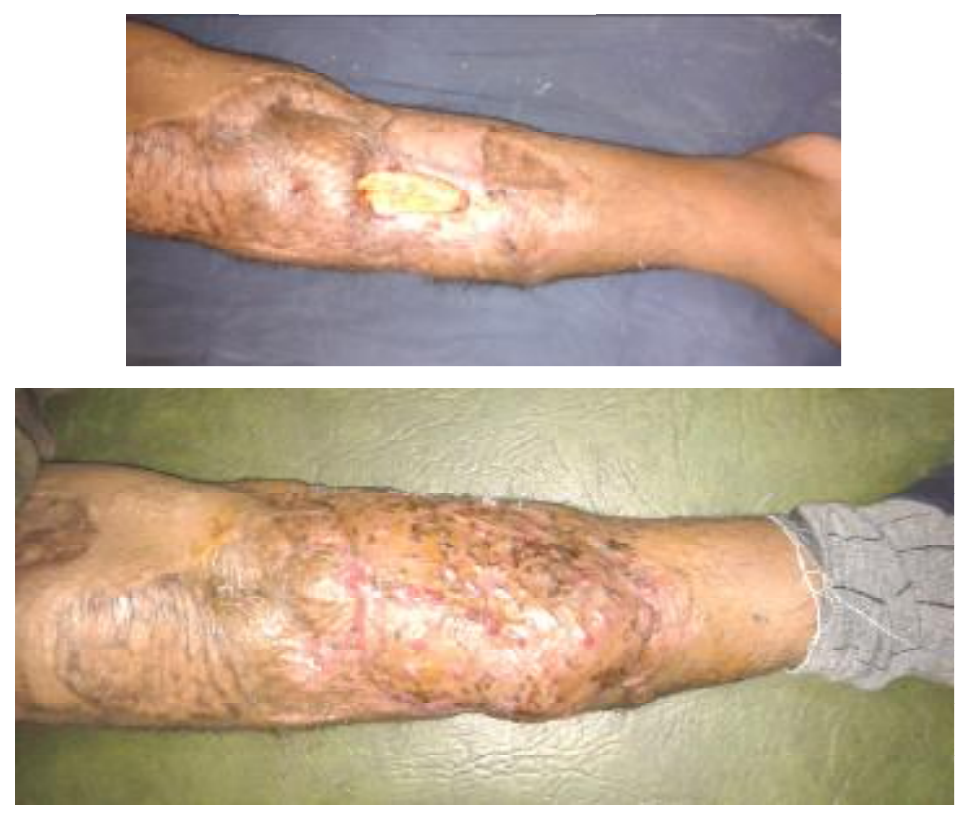

Figure (1): pre and post-operative picture of case 1.

\section{Case (2):}

Male patient, 13 years old, with MCA and raw over the medial malleolus of the Rt. foot. Defect size was $10 * 6 \mathrm{~cm}$.

Free latisimus dorsi flap was done after soft tissue debridement. Anastomosis was done end to end with post. tibial vessels. Ischemia time was 2.5 hours, total operation time was 5.5 hours, hospital stay was 23 days and the donor site was closed primary with no complications. Late post-operative results of the flap and donner site were satisfactory (Fig 2). 
SOHAG MEDICAL JOURNAL

Vol. 21 No.3 october 2017

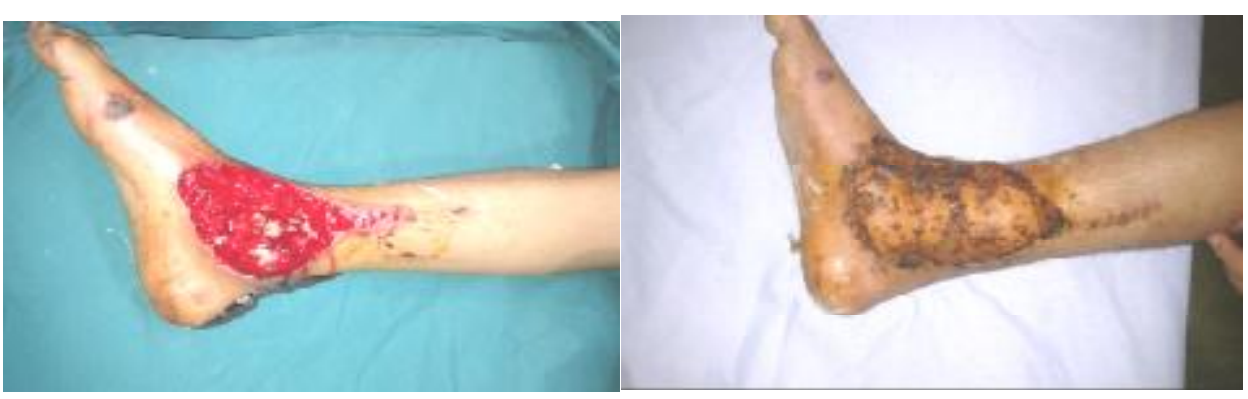

Figure (2): pre and post-operative picture of case 2 .

\section{Discussion}

The lower extremity has a mechanical component and must bear weight. These functional requirements make an effective reconstruction difficult. Moreover, the stress caused by weight-bearing makes durable repair of the foot is difficult and unreliable [4].

Leg trauma, with open high-energy soft-tissue and tibial injuries, most often occurs after motorcycle or car accidents and frequently requires reconstructive surgeon involvement. Tibial fractures are the most common long bone fractures of the body. The anteromedial portion of the tibia is only covered by skin and subcutaneous fat. This relatively unprotected anatomy leads to many instances of bone exposure, which require softtissue coverage.

In a 45 cases with leg and foot defects treated with 47 free flaps, Santanelli et al found that about 50\% of cases were due to trauma [5]. Also in Demirtas et al series of cases, they found that 36 cases out of 53 patients the etiological cause was traumatic [6]. In our study, motor car accident was the commonest cause of injury in accounting for $92.3 \%$ of cases and only one case due to firearm injury and one case secondary to cast sore. Other mechanisms of lower extremity defects includes diabetes and vascular disease, cancer ablation which are less common than trauma.
The free flap has been successfully used for lower extremity reconstruction for the past 40 years. The characteristics of an ideal soft tissue free flap donor for leg and foot reconstruction might be described as having a large skin territory, good color and texture match with the recipient site, a long and large caliber vascular pedicle, reliability for different flap designs, constant pedicle anatomy, acceptable donor-site morbidity, feasibility for a two-team approach, no requirement for major artery or muscle sacrifice, applicability as a flow-through flap, and suitability for usage as a thin flap [7].

Melissinos and Parks reported that the success rate of free flap was $96.8 \%$, $100 \%, 98.8 \%$, and $95.6 \%$ in the reconstruction of defects of the head and neck, the trunk, the upper extremities, and the lower extremities, respectively [8]. Likewise, Percival et al. reported values of $94 \%, 100 \%$, $91 \%$, and $85 \%$, respectively, for the same four types of defects [9]. In our study, complete flap survival was noticed in 12 cases which represent 92.3\% success rate. Reported success rates by many authors with early wound coverage with microvascular free flaps have been $85 \%$ to $100 \%$ [10].

Time interval between the onset of injury and reconstruction was ranged 
between 1 day to 2.5 months with the mean of 31 days.

Most authors argue that early soft tissue coverage is associated with a lower complication rate. Byrd et al. found that the overall complication rate of wounds closed within the first week of injury was $18 \%$ compared with a $50 \%$ complication rate for wounds closed in the subacute phase of 1 to 6 weeks [11].

In a review of Godina's work, closure of wounds within the first 72 hours after injury was associated with the lowest complication rate and highest success rate [12]. Yaremchuk et al. believe that serial, complete debridement is more important than the absolute timing of soft-tissue coverage [13]. Platelet counts increase nearly fourfold in the subacute phase after injury, which may play a role in the increased compilation rate seen during this period.

Recent reviews have had conflicting results. Although Steirt et al found that the free flap coverage of open fractures could be delayed by initial treatment with vacuum-assisted closure (VAC) therapy without significantly increased complication rates [14]. Hou et al. found that the VAC therapy decreased flap size requirements but use beyond 7 days showed higher infection and amputation risks [15].

Although still controversial, it has been recognized that, from several perspectives, such as survival, complication rates, and bone tissue healing, the muscle flap is more advantageous than the fasciocutaneous flap [16] [17] [18].

A musculocutaneous free flap is a good choice to fill dead space due to its large size and ability to bring a greater blood supply to the bone fragments and may be better in preventing osteomyelitis in lower extremity reconstruction [19]. However recent studies have indicated that the ALT flap offers a rich blood supply that can overcome infected wound beds and contribute to the sterilization and healing [20].

Anthony et al. treated 34 patients with chronic osteomyelitis with debridement and immediate muscle flap coverage and antibiotics. They had an overall success rate of $96 \%$ [21]. May reviewed a 13-year experience with treatment of chronic traumatic bone wounds with microvascular free tissue transfer. He had a 95\% success rate in his series of 96 patients [22].

As regarding the overall flap complications, Kang et al experienced an overall complication rate of $36.5 \%$ (19 of 52 patients) [23]. Demirtas et al also had an overall complication rate of $56.5 \%$ (30 of 53 patients) [6]. In retrospective chart review of 74 patients undergoing free tissue transfer for lower extremity limb coverage Christy et al had complication rate of $18 \%$ (13 cases) [24]. In our study, the overall flap complication rate in was $30.8 \%$ (4 of 13 patients). The overall donner site morbidity was $30.8 \%$ in our study which is higher than that of literature 4\% to $10 \%$ [25] [6].

\section{Conclusions}

Traumatic leg and foot defects require collaboration between specialized plastic, vascular and orthopedic surgeons to ensure excellent vascular, bone and soft tissue assessment and to obtain satisfactory and optimum management for the patient.

Resuscitation and management of major life-threatening injuries takes precedence over treatment of the injured lower limb. Priority should be given, therefore, to the identification and control of vascular injury in the immediate post-traumatic period. Debridement of all devitalized tissue is crucial to final success of any reconstruction and often requires serial 
operative debridement prior to final wound coverage.

When free tissue transfer is indicated in leg defect the free latissimus muscle flaps have the following advantages, high success rate, they can cover huge sized defects, better donner site cosmetic results, and wide caliber vascular pedicle, robust blood supply to the recipient area and less need for secondary thinning operations.

\section{References}

1- Fraccalvieri M, Boqetti $P$, and Verna G, et al. (2008): Ditally based fasiocutaneous sural flap for foot reconstruction: a retrospective review of 10 years experience. Foot Ankle Int; 29:191-8.

2- Akhtar S, Hameed A. (2006): Versatility of the sural fasiocutaneous flap in the coverage of lower third leg and hind foot defects. J Plast Reconstr Aesthet Surg; 59:839-45.

3- McGregor IA and Morgan G. (1973): Axial and random pattern flaps. Br J Plast Surg; 26:202-13.

4- Jeng SF and Wei FC (1997). Classification and reconstructive options in foot plantar skin avulsion injuries. Plast Reconstr Surg; 99:1695705

5- Santanelli di Pompeo et al. (2015): Microvascular reconstruction of complex foot defects, a new anatomofunctional classification. Injury Int. J. Care Injured 46: 1656-1663.

6- Demirtas y et al. (2009): comparison of free anterolateral thigh flaps and free muscle-musculocutaneous flaps in soft tissue reconstruction of lower extremity. In Wiley InterScience Microsurgery.

7- Yildirim S, Gideroglu K and Akoz T. (2003): Anterolateral thigh flap: ideal free flap choice for lower extremity soft-tissue reconstruction. J Reconstr Microsurg.; 19:225-233.

8- Melissinos EG and Parks DH (1989): Post-trauma reconstruction with free tissue transfer: analysis of 442 consecutive cases. J Trauma; 29:1095102.
9- Percival NJ, Sykes PJ and Earley MJ (1989): Free flap surgery: the Welsh Regional Unit experience. Br J Plast Surg; 42:435-40.

10- Khouri RK and Shaw WW. (1989): Reconstruction of the lower extremity with microvascular free flaps: a 10-year experience with 304 consecutive cases. J Trauma; 29:1086-1094.

11- Byrd HS, Cienny G III, Tebbetts JB. (1981): The management of open tibial fractures with associated soft tissue loss: External pin fixation with early flap coverage. Plast. Reconstr. Surg.; 68:73-82.

12- Godina M. (1986): Early microsurgical reconstruction of complex trauma of the extremities. Clin Plast Surg.; 13:619.

13-Yaremchuk MJ, Brumback JJ, Manson PN, et al (1982): Acute and definitive management of traumatic osteocutaneous defects of the lower extremity. Plast Reconstr Surg.; 80:114.

14- Steirt AB, Gohritz A, Schreiber TC et al (2009): Delayed flap coverage of open extremity fractures after previous vacuum-assisted closure (VA C) therapy worse or worth? J Plast Reconst Aestht Surg. May; 62(5):6756"83.

15-Hou Z, Irgit K, Strohecker KA, et al. (2011): Delayed flap reconstruction with vacuum-assisted closure management of the open IIIB tibial fracture. J Trauma. 71(6):1705-1708.

16-Calderon W, Chang N, Mathes SJ. (1986): Comparison of the effect of bacterial inoculation in musculocutaneous and fasciocutaneous flaps. Plast Reconstr Surg; 77:785-94.

17- Chang N, Mathes SJ. (1982): Comparison of the effect of bacterial inoculation in musculocutaneous and random-pattern flaps. Plast Reconstr Surg; 70:1-10.

18- Mathes SJ and Nahai F (1982): Clinical applications for muscle and myocutaneous flaps. Mosby, St Louis.

19-Nasir S and Aydin MA (2008): Reconstruction of soft tissue defect of lower extremity with free SCIA/SIEA Flap. Ann Plast Surg; 61:622- 626. 
20- Guerra AB, Gill PS, and Trahan CG, et al. (2005): Comparison of bacterial inoculation and transcutaneous oxygen tension in the rabbit S1 perforator and latissimus dorsi musculocutaneous flaps. J Reconstr Microsurg.; 21:137Y143.

21-Anthony JP, Mathes SJ, Alpert BS (1991): The muscle flap in the treatment of chronic lower extremity osteomyelitis: results in patients over 5 years after treatment. Plast Reconstr Surg 88:311.

22- May JW. Jupiter JB, Gallico GG, et al (1991): Treatment of chronic traumatic bone wounds. Microvascular free tissue transfer: a13-year experience in 96 patients. Ann Surg; 214:241.
23- Kang MJ. Chung CH. Chang YJ. Kim KH. (2013): Reconstruction of the Lower Extremity Using Free Flaps. Arch Plast Surg; 40:575-583.

24- Christy et al (2012): Early Postoperative Outcomes Associated with the Anterolateral Thigh Flap in Gustilo IIIB Fractures of the Lower Extremity. Lippincott Williams \& Wilkins

25- Yazar S, Lin CH, and Lin YT, et al. (2006): Outcome comparison between free muscle and free fasciocutaneous flaps for reconstruction of distal third and ankle traumatic open tibial fractures. Plast Reconstr Surg.; 117:2468Y2475. 